\section{P-203 ハイドロゲル界面人工膜を用いたチャネル電流計測} Lipid Bilayers at the Gel Interface for single Ion Channel Recordings

Toru Ide $(1,2)$ and Minako Hirano (1). (1:Graduate School of Frontier Biosciences, Osaka University; 2:Molecular-Informational Life Science Research Group, RIKEN)

Single channel recording using artificial lipid bilayers is along with the patch-clamp technique a very powerful tool to physiologically and pharmacologically study ion-channels. However, the fragility of the bilayers and the difficulty to incorporate ion-channels into them significantly compromises measurement efficiency. We have developed a novel method for forming artificial lipid bilayers at a hydrogel-water interface that significantly improves the measurement efficiency. Bilayers formed almost instantly and were able to incorporate various types of ion-channel proteins within a short time enabling multichannel measurements. We have also developed a practical method to produce artificial lipid bilayers using a hydrogel-hydrogel interface for ion channel measurements. Bilayers were formed by forcing a hydrogel-bead into contact with the hydrogel plate in a lipid solution. The immediate formation of a bilayer was observed. This allows channel recordings to be repeated more easily and quickly as compared to conventional methods. Currents of various types of channel such as gramicidin, hemolysin, BK-channel, and channels from skeletal muscle SR and Torpedo electric organ have been recorded. These results indicate that these methods can potentially be applied to developing high-throughput screening devices for drug design.

\section{P-204＼cjkstart流動電位測定によるKGSA カリウムチャネルのイオン透過機構の 検討}

Water-ion coupling in ion permeation through KcsA potassium channel revealed by streaming potential measurements

Masayuki Iwamoto(1), Hirofumi Shimizu(1), Shigetoshi Oiki(1). (1: Division of Molecular Physiology and Biophysics, University of Fukui Faculty of Medical Sciences)

Potassium channels permeate $\mathrm{K}^{4}$ ions at rates approaching $10^{8}$ ions per second with strict selectivity. This function is crucial for generating rapid changes in membrane potentials. For KcsA potassium channel, high resolution crystal structures in the closed state have revealed the single-file distribution of ions and water molecules in the pore. Many simulation studies have been performed based on these static pictures, providing microscopic processes in ion permeation. On the other hand, single-channel analyses gave throughput rates of ion conduction. To fill the gaps between microscopic and macroscopic processes of ion permeation, experimental data for the ratios of ion and water flux through the channel are crucial. Here we examined the streaming potential $\left(\mathrm{V}_{\text {stream }}\right)$ of ion permeation in the KcsA channel using liposome patch-clamp technique. $V_{\text {streart }}$ provides a quantitative index of the number of water molecules accompanying a conducting ion (the water-ion coupling ratio), the knowledge of which is a prerequisite for elucidating the coordination of water and ion during permeation. Current-voltage relationship of KcsA currents was recorded under varying osmotic pressure and the $V_{\text {stream }}$ was evaluated as a shift of the reversal potentials. Effects of concentration and species of permeating ions on the $V_{\text {stream }}$ were investigated. Our results provided an essential clue for examining the mechanism of ion permeation through potassium channels.

\section{P-205 1 分子構造変化の可視化によって明らかになったKosA カリウム} チャネルの開閉ねじれ運動

Visualization of conformational changes of single molecular KcsA potassium channels revealed global twisting motions upon gating.

Hirofumi Shimizu(1,2), Masayuki Iwamoto(1,2), Takashi Konno(1,2), Amiko Nihei(4), Yuii C. Sasaki(1,3) \& Shigetoshi Oiki(1,2).(1:CREST Sasaki-team, Japan Science and Technology Corporation;2:Department of Molecular Physiology and Biophysics, University of Fuku Faculty of Medical Sciences; 3.Japan Synchrotron Radiation Research Institute, SPring-8; 4:Engineering Group, SII Nanotechnology Inc.

In the last ten years crystal structures of potassium channels have revealed static pictures of their open and closed conformations. To examine how the channels undergo conformational changes during gating, we took the following method. KcsA potassium channel, which exhibits $\mathrm{pH}$-dependent gating, was fixed on a glass plate with a gold nanocrystal attached to the other end. Synchrotron white $\mathrm{X}$-rays were irradiated and a diffraction spot reflected from the nanocrystal was recorded in video rate. Motions of the channels were figured from the trajectory of the diffraction spots. At neutral $\mathrm{pH}$ where the channel kept closed, restricted Brownian motion was detected. At acidic $\mathrm{pH}$ where the channel underwent gating, twisting motion exceeding 20 degrees was observed, while the bending motion was within the range of 5 degrees. These motions were also observed in the channel fixed in the erect and sideways-laid orientations. This consistent dynamic picture viewed from different viewpoints demonstrated that the channels twisted around the ion permeation pathway upon gating. When the cytoplasmic domain was deleted, the twisting motions were also observed but were slightly enhanced. Moreover, in the presence of a channel blocker, tetrabutylammonium, which bind to the pore in the transmembrane domain, the twisting motion was stopped. From these results, we conclude that the KcsA channel exhibits global twisting motions upon gating with a tight mechanical coupling between the transmembrane and cytoplasmic domains.

\section{P-206 細菌機械受容チャネル MscS の細胞質ドメインの構造変化とチャ} ネルゲーティングの関係

Role of conformational change in the cytoplasmic domain of bacterial mechanosensitive channel MscS in its mechanogating

Hiroaki Machiyama(1), Hitoshi Tatsumi(1) and Masahiro Sokabe(1,2,3). (1: Dept. Physiol., Nagoya Univ. Grad. Sch. Med., 2: ICORP/SORST Cell Mechanosensing, JST, 3: Dept. Mol. Physiol., NIPS)

The bacterial mechanosensitive channel MscS opens upon hypoosmotic shock to protect the cells from lysis. MscS forms a homoheptamer of a subunit composed of transmembrane (TM) and cytoplasmic (CP) domains. Recently we have shown that an electrostatic interaction between TM and CP domains is crucial for channel opening, based on the observation that D62N mutant, which loses TM-CP domains interaction, was hard to open (Nomura et al., Biophys. J., 2008). We also reported that CP domain swells up when MscS opens (Machiyama et al., Ann. Meeting of BSJ, 2007), however, the relationship between the channel opening and $\mathrm{CP}$ domain swelling remains unknown. To address this issue, we constructed wild/F178C and D62N/F178C mutants of which cysteine residues were labeled with Alexa488 and Alexa568 randomly, and measured FRET efficiency to estimate changes in the diameter of CP domain at Phe-178 during channel opening. Both mutants showed decreases in FRET efficiency with a smaller value for D62N/F178C, indicating that the loss of TM-CP interaction decreases the degree of $\mathrm{CP}$ domain swelling. This is the first experimental evidence showing that the $\mathrm{CP}$ domain swelling by tension in the membrane has a crucial role in MscS opening via an electrostatic interaction between TM and CP domains.

\section{P-207 1 分子構造・機能同時計測によるカリウムチャネル (KcsA チャネ ル)の開閉機構の解明}

Simultaneous measurements of optical and electrical properties of potassium channel, KesA

Minako Hirano(1), Yuko Takeuchi(1), Takaaki Aoki(1), Yoshio Yanagida(1), Toru Ide(1,2). (1 Laboratory for Nanobiology, Graduate School of Frontier Bioscience, Osaka University; 2 Molecular-Informational Life Science Research Group. RIKEN)

To clarify the gating mechanism of ion channels, we have tried to simultaneously measure the functional and conformational changes of single ion channels. Here conformational changes of the potassium channel, KcsA, were detected fluorescently.The crystal structure of KcsA was determined in 1998 and a lot of studies on its structure have been done, providing much structural information. At first, based on such information, several sites that are likely to regulate the gating were selected. And amino acids at these sites were exchanged for cysteine and were labeled with an organic dye molecule (tetramethylrhodamine-maleimide). Next, to detect conformational changes accompanied by gating, macroscopic fluorescence intensity was measured under activated $(\mathrm{pH} 4)$ and inactivated condition $(\mathrm{pH} \mathrm{7)}$. Five mutants labeled at the vicinity of a membrane or the cytoplasmic region had large fluorescence intensity difference between $\mathrm{pH} 4$ and $\mathrm{pH} 7$. From these results, these regions are likely to be in different conformation in open and closed state and dynamically change during gating. We will simultaneously measure its current and fluorescence intensity, and clarify the relationship between functional and conformational changes of potassium channel.

\section{P-208 マイクロアレイにおける $\alpha$ マモリシンのポリヌクレオチド輸送} 特性

Transport Property of Polynucleotide Molecules on $\alpha$-Hemolysin Nanopore Array Toshihisa Osaki(1,2), Hiroaki Suzuki(1), Bruno Le Pioufle(3) and Shoji Takeuchi(1,4). (I:Institute of Industrial Science, Univ of Tokyo; 2:LIMMS / CNRS-IIS; 3:SATIE CNRS ENS Cachan; 4:PRESTO, JST)

In this paper, we examine the transport properties of polynucleotide molecules through $\alpha$-hemolysin ( $\alpha$-HL) nanopores, a bacterial membrane ion channel, using a microfluidic chip. The $\alpha$-HL heptamer forms a nanopore of $1.5 \mathrm{~nm}$ in diameter on a bilayer lipid membrane (BLM). Once formed, the nanopore remains open-state and passes a detectable ionic current through the membrane. Since the aperture is comparable to a molecular size, the ionic current will diminish by the penetrating molecule. The recent works focusing on this transport phenomena revealed that the nanopore may provide intensive information on the structure and compesition of single polynucleotide molecules. We, therefore, fabricate the microfluidic, arrayed chip, targeting a parallel recording of the membrane ion-channel currents to realize high throughput analyses of the transport properties. By the simple three-step protocol, we achieve to form planar bilayer lipid membranes in an array format on the chip and to integrate the nanopores into the membranes at once. Here we performed the simultaneous monitoring of the nanopore currents on the microchip, where the signal consisted of stepwise currents from the nanopores and sharp spikes corresponding the transports of a nucleic acid polymer. The features of the blockading spikes successfully discriminate, for instance, the different concentration of the nucleic acid polymer by its frequency. The results promise the high potentiality of our microchip for high-throughput applications, and we report them in detail.

\section{P-209＼cjkstart電位依存性プロトンチャネルのプロトン透過の温度依存性}

Temperature-dependence of Proton Permeation through a Voltage-Gated Proton Channel.

Miyuki Kuno (2), Hiroyuki Ando (1), Hirokazu Morihata (2), Hiromu Sakai (2), Hiroyuki Mori (2), Hirofumi Shimizu (1), Masayuki Iwamoto (1) and Shigetoshi Oiki (1). (1: Dept Molec Physiol \& Biophys, Facult Med Sci, Univ of Fukui; 2: Dept Physiol, Osaka City Univ Grad Sch Med)

The voltage-gated proton channel exists in phagocytotic cells to promote proton flux through the membrane during respiratory burst. The channel shows extreme 
proton selectivity, having single-channel current of $\sim \mathrm{fA}$ at physiological $\mathrm{pH}$. The mechanism underlying proton permeation through the channel has not been elucidated. Here we examined thermodynamic features of proton permeation through the voltage-gated proton channel expressed in microglial cells. A method for rapid temperature change within a few ms under patch-clamp recording (temperature pulse method) was developed and current amplitudes before and after a jump were measured. Current ratios (Iratio), thus obtained, represent permeability ratios at different temperatures, giving Q10 for proton permeation. Iratios were measured in various experimental conditions in a wide temperature range of 4 to 49 degree. We found that Q10 for proton permeation decreased monotonically at higher temperature. The Arrenius plot demonstrated convex curvature, suggesting that mixed events are underlying. Theoretical studies for proton transfer around a channel suggested non-trivial contribution of diffusion-limited access of proton towards the pore entrance. A novel resistivity pulse method revealed relative resistance of the access process to the total resistance. Then, the measured temperature dependence of Q10 was decomposed for those of the permeation through the channel and the access region. Q10 for proton permeation through the voltage-gated proton channel was unveiled as $\sim 2.5$.

\section{P-210 クラミドモナスの TRP チャネルの分子生物学的解析}

Molecular analysis of the transient receptor potential channels in Chlamydomonas Kenta Fujiu(1), Yoshitaka Nakayama(2), Masahiro Sokabe(1, 3, 4), and Kenjiro Yoshimura(1 2). (1:JST/SORST, Mechanosensing Project, Nagoya, Japan; 2:Div. Struc. Biosci., Grad. Sch Life Environ. Sci., Univ. Tsukuba, Japan; 3:Dept., Physiol. Nagoya Univ. Grad. Sch. Med. Nagoya, Japan; 4:Dept. Mol. Physiol., Natl. Inst. Physiol. Sci., Okazaki, Japan)

Chlamydomonas cells sense various environmental signals such as mechanical, chemical, thermal, gravitational, and electrical stimulus, but their molecular mechanisms are mostly unknown. In the higher eukaryotes, transient receptor potential (TRP) channel family proteins are responsible for detecting broad range of environmental factors including mechanical, ligand, thermal, and osmotic stimulus. We hypothesized that TRP channels function in the sensing mechanism of Chlamydomonas. We identified putative TRP channel genes from Chlamydomonas genomic database and found by RT-PCR that eight genes are expressed. PKD2 gene identified by Huang et al (2007) was present on the list. Sequence analysis indicated that four genes had ANK repeat motif suggesting that they may interact with other proteins. Phylogenetic analysis demonstrated that Chlamydomonas TRP channels are distributed in several subfamilies of TRP channels. Western blot analysis using specific antibodies raised against each TRP channels showed that three TRP channel are present in the flagella. Immunofluorescence staining further indicated that the three TRP channels are located along the length of the flagella. The present result suggests that some ChlamydomonasTRPs may function as a flagellar sensory channel.

\section{P-211 クロルプロマジンによる細菌機械受容チャネル MscL の活性化機} 構

Activation mechanism of bacterial mechanosensitive channel MscL by chlorpromazine

Takeshi Nomura (1), Kenjiro Yoshimura (1,2) and Masahiro Sokabe $(1,3,4),(1$ : ICORP/SORST, Cell-Mechanosensing Project, JST 2: Structural Biosciences, Graduate School of Life \& Environmental Sciences, University of Tsukuba 3: Dept Physiology, Nagoya University Graduate School of Medicine 4 :Dept Molecular Physiology, NIPS

The bacterial MscL (mechanosensitive channel of large conductance) is the first cloned and best understood mechanosensitive (MS) channel to date owing to its resolved 3D structure by X-ray crystallography. MscL is known to be activated exclusively by tension in the membrane and its tension sensing amino acids, typically F78, has been identified near the lipid-water interface of the outer leaflet of the bilayer. It is supposed that increased tension in the membrane would drag F78 to tilt down the transmembrane $\alpha$-helicies, leading to the opening of the closed gate located in the inner leaflet of the bilayer. However, detailed mechanisms how the sensed force will open the gate is poorly understood. The amphipath chlorpromazine (CPZ), which is supposed to be inserted preferentially in the inner leaflet of the lipid bilayer, can activate MscL in a dose-dependent manner. Information on the mechanism of the CPZ effect is expected to provide us deeper insight into the mechanical gating mechanism of MscL. The simplest hypothesis for the mechanism of the CPZ effect is that the drug generates a stress in the membrane equivalent to the stress by membrane stretch. To address this issue, we investigated whether $\mathrm{CPZ}$ can activate the tension-tolerant mutant $\mathrm{F} 78 \mathrm{Y}$ MscL that lacks tension sensing site. We found that CPZ activates F78Y MscL, suggesting that $\mathrm{CPZ}$ bypasses the tension sensing process and modifies the structures that locates near the gate and stabilizes the closed state.

\section{P-212 アクアポリン 4 再構成プロテオリポソームの水透過性は塩化水銀 により減少する \\ Mercury Chloride Decreases the Water Permeability of} Aquaporin-4-Reconstituted Proteoliposomes

Yoshinori Yukutake(1), Shoji Tsuji(1), Yoshinori Hirano(1), Takeshi Adachi(2), Toshiyuki Takahashi(3), Kazuo Fujihara(3),Makoto Suematsu(2), Masato Yasui(1)(1:Deptof Pharmacology, 2:Biochemistry \& Integrative Medical Biology, School of Medicine, Keio Univ 3:Dept of Neurology, Tohoku Univ Graduate School of Medicine

Mercurials inhibit aquaporins (AQPs), and site-directed mutagenesis has identified Cys 189 as a site of the mercurial inhibition of AQP1. On the other hand AQP4 has been considered a mercury-insensitive water channel because it does not have the reactive cysteine residue corresponding to Cys 189 of AQP1. Indeed, the water permeability of AQP4 expressed in various types of cell, is not inhibited by $\mathrm{HgCl}^{2+}$. To examine the direct effects of mercurials on AQP4 in proteoliposome reconstitution system. The water permeability of AQP4-proteoliposomes with or without $\mathrm{HgCl} 2$ was measured with a stopped-flow apparatus. Surprisingly, the osmotic water permeability of AQP4-proteoliposomes was significantly decreased by $5 \mu \mathrm{M} \mathrm{HgCl} 2$ within 30 seconds, and this effect was completely reversed by $\beta$-mercaptoethanol. The dose- and time-dependent inhibitory effects of $\mathrm{Hg}^{2+}$ suggest that the sensitivity to mercury of AQP4 is different from that of AQP1. Site-directed mutagenesis of six cysteine residues of AQP4 demonstrated that Cys178, which is located at loop D facing the intracellular side, is a target responding to $\mathrm{Hg}^{2+}$. We confirmed that AQP4 is reconstituted into liposome in a bidirectional orientation. Our results suggest that mercury inhibits the water permeability of AQP4 by mechanisms different from those for AQP1 and that AQP4 may be gated by modification of a cysteine residue in cytoplasmic loop D.

3P-213 ポリアルギニンーナノパーティクル複合体の脂質二分子膜透過 The poly(Arg) - nanoparticle complexes translocate through lipidbilayer membranes.

Satoru Ueno, Saburo Shimabayashi. (The University of Tokushima Institute of Health Biosciences, Graduate School Division of Physical Pharmacy)

Introduction Several reports have suggested that certain short natural and synthetic water-soluble cationic peptides which mainly translocate various cell membranes by endocytically show the non-endocytically translocation and we reported that cationic polypeptide: poly-L-arginine (poly(Arg)) and poly(Arg) BSA complex directly translocate negatively charged liposome membrane. We have been investigating the complexation of poly(Arg) - nanoparticle (hydroxyapatite (hap), Multiwalled Carbon Nanotube (mwct)) complex and translocationability of poly(Arg) - nanoparticle complexes through negatively charged phospholipid (soybean phospholipid (SBPL)) bilayer membranes by several instruments. MethodsWe have studied the complexation of poly(Arg) and nanoparticles by zeta-potential measurement and the transfer of complexes across the liposome membrane by fluorescence, $\mathrm{CD}$, and conforcal laser microscope (CLSM). Results and Discussion After the nanoparticle dispersion was mixed with the poly(Arg) solution, the zeta-potentials were positively sifted. This zeta-potential shift was concluded adsorption of poly(Arg) on the nanoparticle surface and the formation of the complex. By the CLSM measurement, We find that both complexes can translocate through the negatively charged liposome membranes.

3P-214 ルミラー膜に吸着したバクテリオロドプシンの起電性

Electrogenic activity of bacteriorhodopsin adsorbed on Lumirror membrane

Eiro Muneyuki, Toshihiro Higaki, Makoto, Matsumoto, Takumi Yamada, Tetsuaki Okamoto, Shoichi Toyabe (Dept. Physics, Faculty of Science and Engineering, Chuo University)

Previously, we developed an assay system for the measurement of capacitive electric currents generated by ion pumps using the thin polymer film 'Lumirror' (FEBS Lett. 427,109-114 (1998)). This system enabled us to examine the electrogenicity of ion pumps over a wide range of experimental conditions with high reproducibility due to the mechanical and chemical stability. In the present study, we compared the electrogenicity of bacteriorhodopsin adsorbed onto the Lumirror membrane with a simple equivalent electric circuit. The electrogenicity was well explained by the equivalent circuit and experimental results obtained at various light intensity suggested that the electrogenicity of bacteriorhodopsin was independent of the light intensity. Now we are examining the photoelectric response of bacteriorhodopsin under various conditions and comparing the results with the behavior of the equivalent circuit.

3P-215 COPII 小胞形成における輸送されないタンパク質の排出機構 Exclusion of non-transport protein on COPII vesicle formation process.

Kazuhito V. Tabata (1), Ken Sato(2), Toru Ide(3), Takayuki Nishizaka(4), Akihiko Nakano(5), Hiroyuki Noji(1). (1: ISIR, Osaka Univ,; 2: Dept Life Sciences, Graduate School of Arts and Sciences., Univ. of Tokyo; 3: Graduate School of Frontier Biosciences, Osaka Univ.; 4: Dept of Physics, Gakushuin Univ.; 5: Molecular Membrane Biology, RIKEN)

In eukaryotic cells, coat protein complex II (COPII) is responsible for the vesicle formation from endoplasmic reticulum membrane. The released vesicles from ER membrane diffuse or are moved on cytoskeleton to Golgi complex in order to transport particular cargo proteins. This vesicle formation was reconstituted in vitro from a SNARE protein (Bet1p), a small GTPase (Sar1p), and two COP II coat protein complexes (Sec23/24p and Sec13/31p)[Sato, K and Nakano, A., Nat Struct. Mol. Biol., 2005]. In previous annual meeting, we reported that the vesicle budding and the cluster formation of COPII components by the Sec13/31p occurred from an artificial lipid bilayer formed on microscope stage. In addition, we indicated that the GTP hydrolysis was important for a condensation of transport substrate (Betlp) into the COPII vesicle. In this presentation, we will show the active exclusion of non-transport protein (Ufe1p) by the COPII minimum components. The Ufelp was fluorescently labeled with $\mathrm{Cy} 3$, and reconstituted with the non-labeled Bet1p into the artificial lipid bilayer. When the COPII minimum components were added to the system containing GTP or GMP-PNP, the fluorescent intensity of the cluster under the GMP-PNP condition was around three times higher than the GTP condition. It suggests that the GTP hydrolysis actively excluded the Cy3-Ufe $1 p$ from the COPII cluster. We will also discuss about the concentration and the exclusion system by COPII minimum components. 